\title{
Isolation and characterization of indole acetic acid (IAA) producing bacteria from rhizospheric soil and its effect on plant growth
}

\author{
B. Mohite \\ Department of Biotechnology, Moolaji Jaitha College, Jalgaon - 425001(MS), India. "Corresponding author: mohite_bhavna@ \\ rediffmail.com
}

\begin{abstract}
Indole acetic acid (IAA) production is a major property of rhizosphere bacteria that stimulate and facilitate plant growth. The present work deals with isolation, characterization and identification of indole acetic acid producing bacteria from the rhizospheric soil. Out of ten Indole acetic acid producing isolates, five were selected as efficient producers. Optimization of indole acetic acid production was carried out at different cultural conditions of $\mathrm{pH}$ and temperature with varying media components such as carbon and nitrogen source, tryptophan concentration. Partial purification of IAA was done and purity was confirmed with Thin layer chromatography. Subsequently, effect on plant growth was tested by pot assay. In conclusion the study suggests the IAA producing bacteria as efficient biofertilizer inoculants to promote plant growth.
\end{abstract}

Keywords: Tryptophan, rhizobacteria, purification, optimization, plant nutrition

\section{Introduction}

Indole acetic acid (IAA) is one of the most physiologically active auxins. IAA is a common product of L- tryptophan metabolism produced by several microorganisms including Plant GrowthPromoting Rhizobacteria (PGPR) (Lynch, 1985). Bacteria that colonize the rhizosphere and plant roots, and enhance plant growth by any mechanism are referred to as PGPR. PGPR can exhibit a variety of characteristics responsible for influencing plant growth. The common traits include production of plant growth regulators (like auxin, gibberellin, and ethylene), siderophores, $\mathrm{HCN}$ and antibiotics (Arshad et al., 1992). Bacteria synthesize auxins in order to perturb host physiological processes for their own benefit (Shih-Yung, 2010). The microorganisms isolated from rhizosphere region of various crop have an ability to produce Indole acetic acid as secondary metabolites due to rich supply of substrates. Indole acetic acid helps in the production of longer roots with increased number of root hairs and root laterals which are involved in nutrient uptake (Datta and Basu, 2000). IAA stimulates cell elongation by modifying certain conditions like, increase in osmotic contents of the cell, increase in permeability of water into cell, decrease in wall pressure, an increase in cell wall synthesis and inducing specific RXA and 
protein synthesis. It promotes embial activity, inhibit It promotes embial activity, inhibit or delay abscission of leaves, induce flowering and fruiting. (Zhao, 2010)

IAA is a metabolite derived from Trp by many Trpdependant and Trp-independent pathways in plants and bacteria. More than one pathway could be present in a bacterium (Pattern and Glick, 1996). Physiological evidence for different Trp-dependent pathways for synthesis in Azospirillum brasilense has been reported (Carreno-Lopez et al., 2000). In Trp dependant pathway, tryptophan is converted to indole3-acetamide (IAM) by tryptophan-2-monooxigenase and IAM is metabolized to IAA by IAM-hydrolase (Matsukawa et al., 2007). Horemans and Vlassak (1985) demonstrated that $A$. brasilense could produce IAA in the absence of tryptophan when grown aerobically showed that the highest levels of auxin were produced in the presence of $\mathrm{NH}_{4}$. It appears to be of particular importance during embryogenesis, when fine control over low levels of IAA is critical to polar development. Trp-independent pathway might contribute significantly to the newly synthesized IAA; however, extensive Trp-to-IAA conversion also occurs in such preparations. The first objective of this study was to isolate and screen indigenous Indole acetic acid producing bacteria from different rhizospheric soil. The second was to purify the IAA and screen their abilities of plant growth promoting rhizobacteria attributes. Besides, optimization study intended for high IAA production was carried out with physicochemical parameters such as carbon and nitrogen source, with and without supplement of tryptophan, $\mathrm{pH}$ and temperature.

\section{Materials and Methods}

\subsection{Isolation of IAA producing bacteria from rhizospheric soil}

Ten soil samples each from banana, cotton, maize and wheat rhizosphere were collected. Physicochemical analysis of samples based on soil texture, $\mathrm{pH}$ and temperature was done. The soil texture was slit, $\mathrm{pH}$ in the range of 7.5 to 8.5 and temperature was 30 to 32 ${ }^{\circ} \mathrm{C}$. The isolation of the microorganisms was done as follows. $10 \mathrm{~g}$ of rhizosphere soil in $250 \mathrm{~mL}$ flask was taken and $90 \mathrm{~mL}$ sterile distilled water was added. It was incubated on rotary shaker at $120 \mathrm{rpm}$ for $10 \mathrm{~min}$. $1 \mathrm{ml}$ sample was serially diluted upto $10^{-7} .0 .1 \mathrm{~mL}$ of diluted sample was plated on sterile Luria Bertani (LB) agar medium (Himedia, India) and incubated for 3 days at $28{ }^{\circ} \mathrm{C}$. Single colonies were picked up and streaked on sterile LB agar plates to get pure culture. Well isolated colonies were observed for morphological characterization.

Total 10 isolates were obtained from different rhizospheric soil. The isolates were further checked for IAA production.

\subsection{Identification of isolates}

The isolates based on micromorphological observation and biochemical characterization were identified. The tests involved, were Gram staining, amylase and gelatinase, catalase like enzyme production, citrate utilization, indole test, Vogus Proskaur test, methyl red test, $\mathrm{H}_{2} \mathrm{~S}$ production, sugar fermentation etc. (Aneja, 2001).

\subsection{Characterization of IAA production}

To determine the amounts of IAA produced by each isolate, a colorimetric technique was performed with Van Urk Salkowski reagent using the Salkowski's method (Ehmann, 1977). The isolates were grown in yeast malt dextrose broth (YMD broth) (Himedia, India) and incubated at $28{ }^{\circ} \mathrm{C}$ for 4 days. The broth was centrifuged after incubation. Supernatant was reserved and $1 \mathrm{ml}$ was mixed with $2 \mathrm{ml}$ of Salkowski's reagent $\left(2 \% 0.5 \mathrm{FeCl}_{3}\right.$ in $35 \%$ $\mathrm{HCLO}_{4}$ solution) and kept in the dark. The optical density (OD) was recorded at $530 \mathrm{~nm}$ after $30 \mathrm{~min}$ and $120 \mathrm{~min}$. 
IAA production was compared in YMD and LB media. YMD medium was compared with and without tryptophan.

\subsection{Extraction and purification of IAA}

Isolates were cultivated in YMD broth and it was centrifuged by Beckman centrifuge SW 40 Ti rotor with $17738 \times \mathrm{g}$ for $15 \mathrm{~min}$. The supernatant was collected and mixed with ethyl acetate (1: 2). After vigorous shaking it was allowed to stand for $10 \mathrm{~min}$. IAA was extracted within solvent layer. The procedure was repeated 3 to 4 times.

\section{Thin layer chromatography}

TLC slide was prepared with silica gel $G$ and calcium carbonate. Propanol: Water (8:2) was used as Solvent system. The extracted sample and standard IAA $(10 \mathrm{mg} / 100 \mathrm{ml})$ were spotted on TLC plate. Chromatogram was developed with the Salkowski's reagent (Kuang-Ren et al., 2003).

\subsection{Optimization of media and physical factors for IAA production}

Optimization of carbon and nitrogen source, tryptophan concentration and process parameters such as $\mathrm{pH}$, temperature were made for improved yield of IAA by one factor at a time analysis. The effect of $\mathrm{pH}$ was tested in the range of 5 to 9 using buffered broth prepared in phosphate buffer. YMD medium with tryptophan supplement was used as basis for optimization of IAA production.

\subsection{Effect of IAA producing isolates on plant growth by pot assay}

To study the effect of IAA producing rhizospheric isolates on plant growth, pot assay was performed. Local wheat (var. Lokvan) seeds were used for seed coating. The wheat seeds were surface sterilized by immersing in $95 \%$ ethanol for $30 \mathrm{~s}$ and mercury chloride $(0.2 \%)$ for $3 \mathrm{~min}$. Then further to remove traces of mercury chloride, the disinfected seeds were washed 5 times by sterile distilled water. $0.1 \mathrm{ml}$ overnight grown culture (0.5 OD) was applied on seed surface for seed coating. Seeds were dried and sowed into sterile soil as carrier. Six seeds were sown in each pot used per pot at equal distance and experiment was performed in triplicates for each isolates. The uncoated seeds were used as control. After appearing seedlings of soil $0.1 \mathrm{~g}$ of Trp per $\mathrm{kg}$ soil after being solving in water was added to every pot. Pots were irrigated with sterile distilled water every day and kept in sunlight. At the interval of every 5 th day, plant was uprooted and seedlings were measured for shoot and root length and chlorophyll content upto 15 th day.

\section{Results}

\subsection{Isolation and Identification of rhizospheric isolates}

10 bacterial isolates were successfully isolated as IAA producer from rhizosphere soil among which 5 were selected based on IAA production ability. The isolates were coded as br1, br2, br3 (from banana rhizosphere), wr2 (from wheat rhizosphere) and mr2 (from maize rhizosphere).

The isolates were identified based on morphological observation and biochemical characterization (Table 1). Bergey's manual of determinative of bacteriology was used as a reference to identify the isolates (MacFaddin, 2000). The isolates were identified as B. megaterium, Lactobacillus casei, B. subtilis, B. cereus and Lactobacillus acidophilus, respectively for isolates coded as br1, br2, br3, wr2 and mr2 based on Bergey's manual. 
Table 1. Morphological and Biochemical characterization of IAA producing rhizospheric isolates

\begin{tabular}{|c|c|c|c|c|c|}
\hline \multirow[b]{2}{*}{ Characteristics } & \multicolumn{5}{|c|}{ Isolates from rhizosphere } \\
\hline & br1 & br2 & br3 & $\mathrm{mr} 2$ & wr2 \\
\hline Gram Staining & Gram positive & Gram positive & Gram positive & Gram positive & Gram positive \\
\hline Shape & Rod & Rod & Rod & Rod & Rod \\
\hline Motility & Positive & Positive & Positive & Positive & Positive \\
\hline Capsule staining & Positive & Positive & Positive & Positive & Positive \\
\hline Acid Fast nature & Negative & Negative & Negative & Negative & Negative \\
\hline Endospore & Positive & Negative & Positive & Negative & Positive \\
\hline Oxygen Requirement & Aerobic & Aerobic & Aerobic & Aerobic & Aerobic \\
\hline Colony & Off white & White & White & Pale yellow & Off white \\
\hline Catalase & Positive & Negative & Positive & Negative & Positive \\
\hline Urease & Positive & Positive & Positive & Positive & Positive \\
\hline Amylase & Positive & Positive & Positive & Positive & Positive \\
\hline Protease & Positive & Positive & Positive & Positive & Positive \\
\hline Pectinase & Positive & Positive & Positive & Positive & Positive \\
\hline $\mathrm{H}_{2} \mathrm{~S}$ production & Negative & Negative & Negative & Negative & Negative \\
\hline Indole Production & Negative & Negative & Negative & Negative & Positive \\
\hline Methyl red test & Negative & Negative & Negative & Negative & Positive \\
\hline Vogus Proskaur Test & Negative & Negative & Positive & Negative & Negative \\
\hline Citrate Utilization & Positive & Positive & Positive & Positive & Positive \\
\hline Glucose & Positive & Positive & Positive & Negative & Negative \\
\hline Mannitol & Positive & Positive & Positive & Negative & Negative \\
\hline Sucrose & Positive & Positive & Positive & Positive & Positive \\
\hline Xylose & Negative & Negative & Negative & Negative & Negative \\
\hline
\end{tabular}




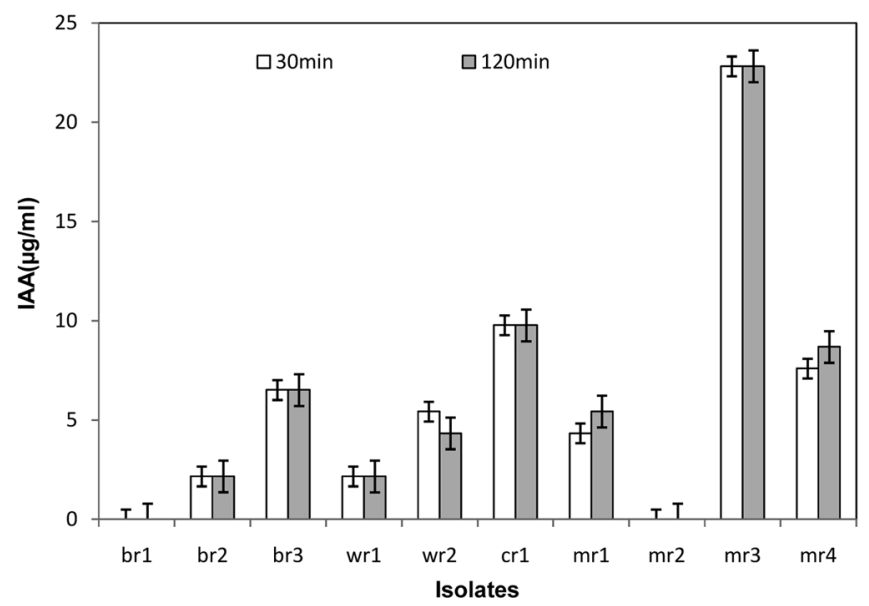

Figure 1. Comparision of IAA production by the bacterial isolates in LB medium with tryptophan $\left(\mathrm{n}=3^{*}\right)$

a)

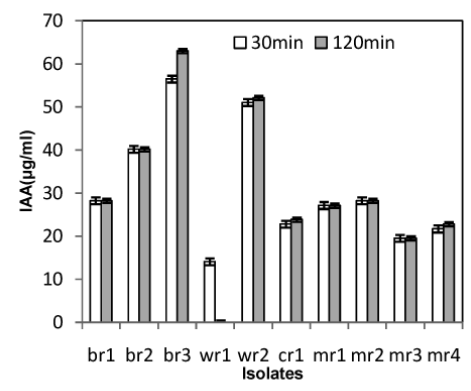

b)

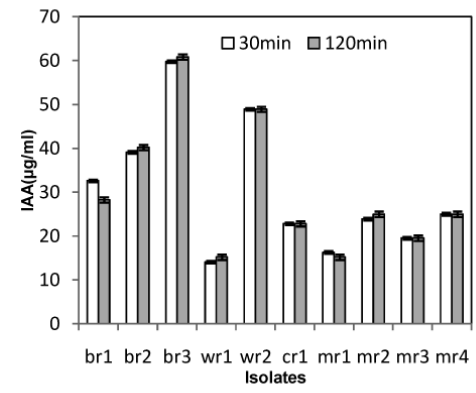

Figure 2. Comparision of IAA production by the bacterial isolates in YMD medium a) without tryptophan and b) with tryptophan $\left(\mathrm{n}=3^{*}\right)$

\subsection{Characterization of IAA production potential}

IAA production was checked with use of Salkowski reagent. Color development was first visible at the highest IAA concentration within minutes and continued to increase in intensity for a period of $30 \mathrm{~min}$. Hence optical density was measured after 30 and $120 \mathrm{~min}$. If colour development was not observed after $30 \mathrm{~min}$, it was not kept for further incubation upto $120 \mathrm{~min}$.
IAA production when compared between YMD and LB media, the production of IAA was more in YMD media (Figure 1 and 2a). YMD media with tryptophan was more suitable for IAA production compared with YMD without tryptophan as reported earlier (Figure $2 \mathrm{a}$ and $2 \mathrm{~b})$. The results were in support to previous study (Ghosh and Basu, 2002). 


\subsection{Detection of IAA by thin layer chromatography}

Purified IAA sample was compared with standard IAA on TLC chromatograms. TLC of ethyl acetate extract showed pink colour spot at the Rf corresponding to the authentic IAA (0.57) as shown in Figure 3. It confirmed IAA producing potential of rhizospheric isolates.

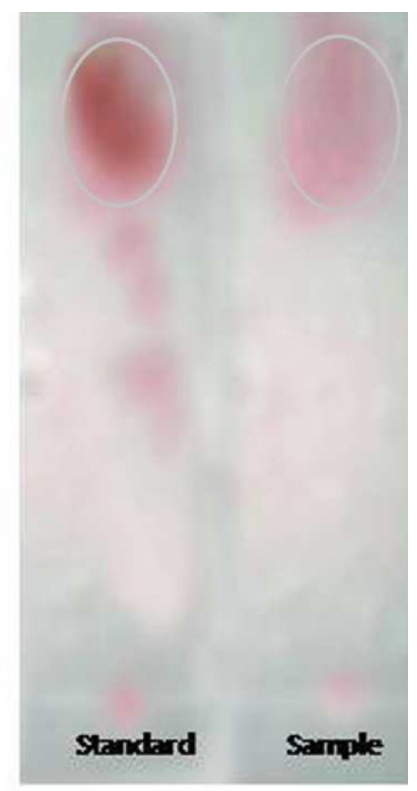

Figure 3. Thin layer chromatogram of bacterially sized IAA detected by Salkowiski's reagent compared with standard

\subsection{Effect of Different Carbon and Nitrogen Sources on IAA production}

The mannitol (as carbon source) and ammonium nitrate (as nitrogen source) in addition to tryptophan was tested as carbon and nitrogen sources for IAA production (Figure 4a). The most suitable carbon source for IAA production was glucose for brl, Mannitol for br2 and br3, Glucose and Sucrose for $\mathrm{mr} 2$ while Glucose and Mannitol for wr2. The suitable nitrogen source for IAA production was different with the isolate type as $\mathrm{NaNO}_{3}$ for br1, $\mathrm{KNO}_{3}$ and peptone for br2. $\mathrm{KNO}_{3}$ and peptone for br3 and $\mathrm{mr} 2$ while $\mathrm{NaNO}_{3}$ and peptone for wr2 (Figure 4b). There was a significant difference between the concentrations of IAA which indicates the effect of nitrogen. Basu and Ghosh (2001) have reported that Glucose and $\mathrm{KNO}_{3}$ as the best carbon and nitrogen sources of IAA production by Rhizobium spp. Shilts et al. (2005) have reported high IAA production in medium containing mannitol and galactose.

\subsection{Effect of L-Tryptophan concentration on IAA}

L-Tryptophan is generally considered as an IAA precursor; because of its addition to IAA producing bacterial culture enhances IAA biosynthesis (Costacurta and Venderleyden, 1995). All 5 isolates preferred Tryptophan for IAA production. Maximum IAA production was found in the medium amended with $0.1 \%$ tryptophan for br $1, \mathrm{br} 2$ and $\mathrm{br} 3,1.5 \%$ for $\mathrm{mr} 2$ and $0.05 \%$ wr2 (Figure $5 \mathrm{a}$ ).

IAA was not produced or produced in negligible quantity in the L-Tryptophan free medium. There was a significant differentlevelofL-tryptophanforvaryingmicroorganisms. For many bacteria, the conversion of tryptophan into IAA is most important. Manulis et al. (1994) have reported various Stryptomyces spp. that secrete Indole 3-acetic acid (IAA) when fed with tryptophan while Swain et al. (2007) have reported IAA producing Bacillus subtilis spp. Tryptophan dependant IAA synthesis had been also determined in several other bacteria (Patten and Glick, 2002). In Enterobacter Cloacae, IAA was synthesized via indole-3 pyruvic acid (Koga et al., 1991). In Pseudomonas syringae, IAA biosynthesis occurs mostly from tryptophan via indole-3 acitamide (Kosuge and Sanger, 1987) and in Pseudomonas fluorescens, tryptophan bypassing the indole 3-actaldehyde, which is further converted into IAA (Oberhansli et al., 1991). IAA synthesis has also been found to occur via tryptamine in a Agrobacterium tumefaciens and via indole 3-acetonitreile in Alcaligenes faecalis and A. tumefaciens (Costacurta and Vanderleyden, 1995). 

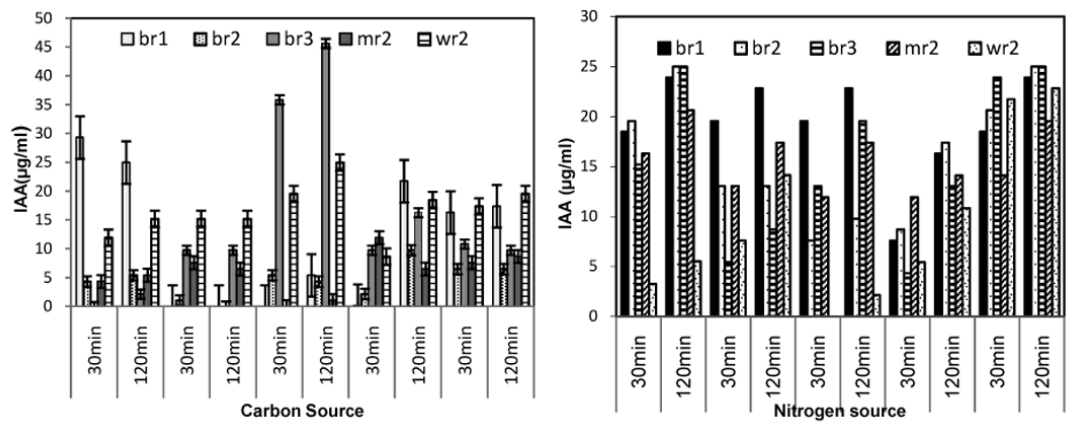

Figure 4. Effect of a) carbon and b) nitrogen sources on biosynthesis of IAA by the bacterial isolates grown in YMD medium supplemented with tryptophan $\left(\mathrm{n}=3^{*}\right)$
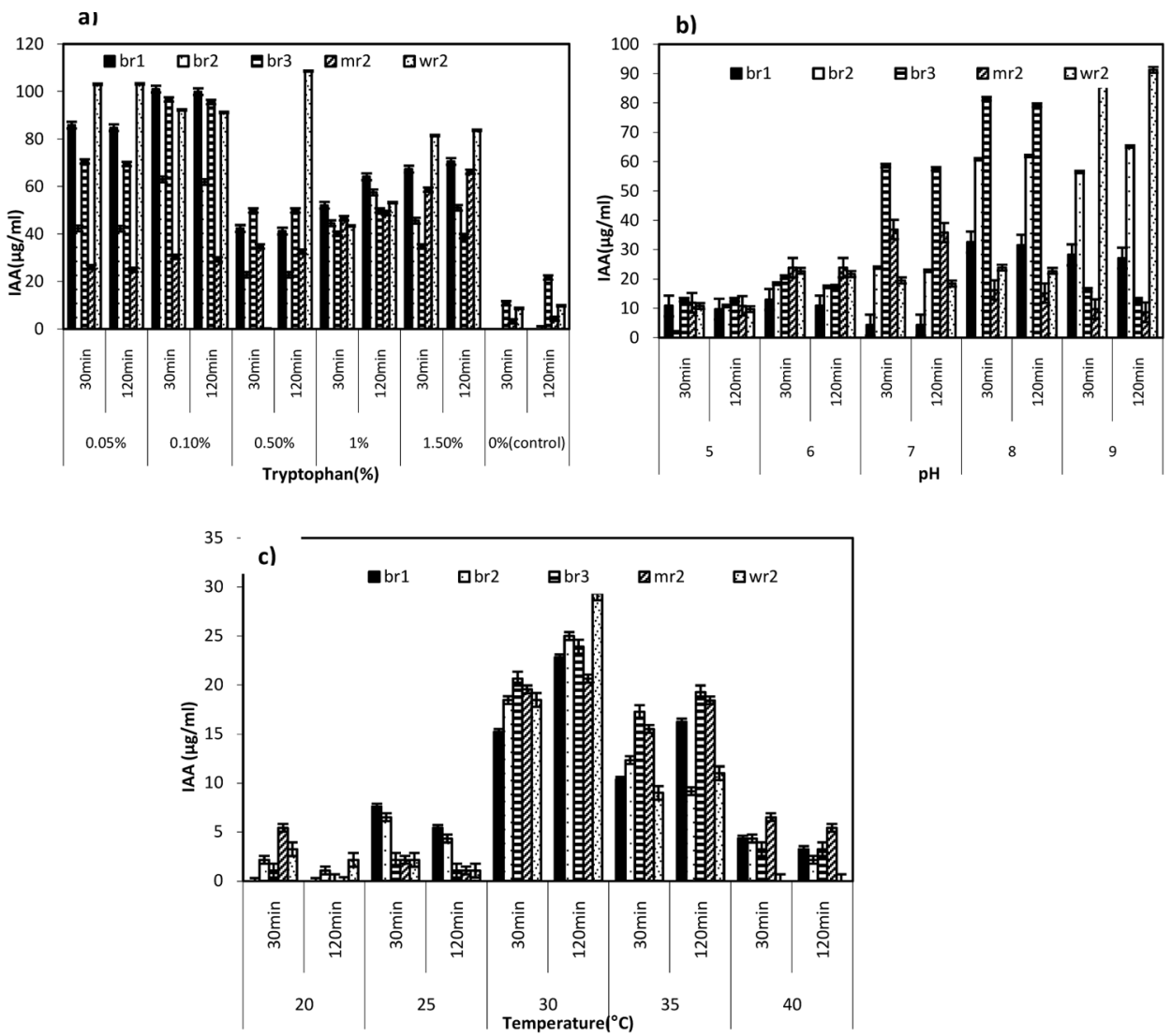

Figure 5. Effect of a) tryptophan concentration b) $\mathrm{pH}$ and c) temperature on biosynthesis of IAA by the bacterial isolates grown in YMD medium supplemented with tryptophan $\left(n=3^{*}\right)$ 
Microbial biosynthesis of IAA in soil is enhanced by tryptophan from root exudates or decaying cells. The application of organic fertilizer can increase the levels of tryptophan in soil and tryptophan found in organic wastes and fertilizers may be produced by aerobic or anaerobic microbial transformation (Arkhipchenko et al., 2006).

\subsection{Effect of $\mathrm{pH}$ and temperature on IAA production}

The low $\mathrm{pH}$ limits plant growth, because the concentrations of metals $\left(\mathrm{Al}^{3+}\right.$ and $\left.\mathrm{Mn}^{2+}\right)$ in the soil solution can reach toxic levels. It is known that soil $\mathrm{pH}$ and metal cations may affect many processes occurring in the rhizosphere. The impact of different levels of $\mathrm{pH}(5-9)$ was determined. The maximum amount of IAA was produced when $\mathrm{pH}$ of the culture medium was 8 for isolates br1, br2, br 3 while $\mathrm{pH} 7$ for $\mathrm{mr} 2$ and $\mathrm{pH} 9$ for wr2 (Figure 5b). Acidic $\mathrm{pH}$ (below 6) was found to be unfavorable for IAA production. The effect of different ranges of temperature (20 $40{ }^{\circ} \mathrm{C}$ ) was studied. The optimum temperature for IAA production was $30{ }^{\circ} \mathrm{C}$ (Figure $5 \mathrm{c}$ ). According to Sudha et al. (2012) $37^{\circ} \mathrm{C}$ temperature was optimum for
Rhizobium and Bacillus spp. for IAA production. Mandal et al. (2007) have reported the Rhizobium strain VMA 301 for elaborated high levels of IAA production in a medium having $\mathrm{pH}$ 7.2. Khamna et al. (2010) have reported temperature $30{ }^{\circ} \mathrm{C}$ and $\mathrm{pH}$ 7.0 was suitable for maximum IAA production by Streptomyces sp.

\subsection{Biological feasibility of Rhizobacteria for plant growth}

The rhizosphere soil isolates were significantly augment the plant height and root length of wheat seedlings along with increase in chlorophyll content when compared with control (Figure 6, Table 2). In earlier report, root elongation was found to occur in Sesbania aculeata by inoculation with Azotobacter spp. and Pseudomonas spp., in Brassica campestris by Bacillus spp (Ghosh et al., 2003), in Vigna radiata by Pseudomonas putida (Patten and Glick, 2002) and in Pennisetum americanum by Azospirillum brasilense (Tien et al., 1979). This indirectly confirms the involvement of bacterial isolates in enhancing the plant growth by synthesizing IAA.

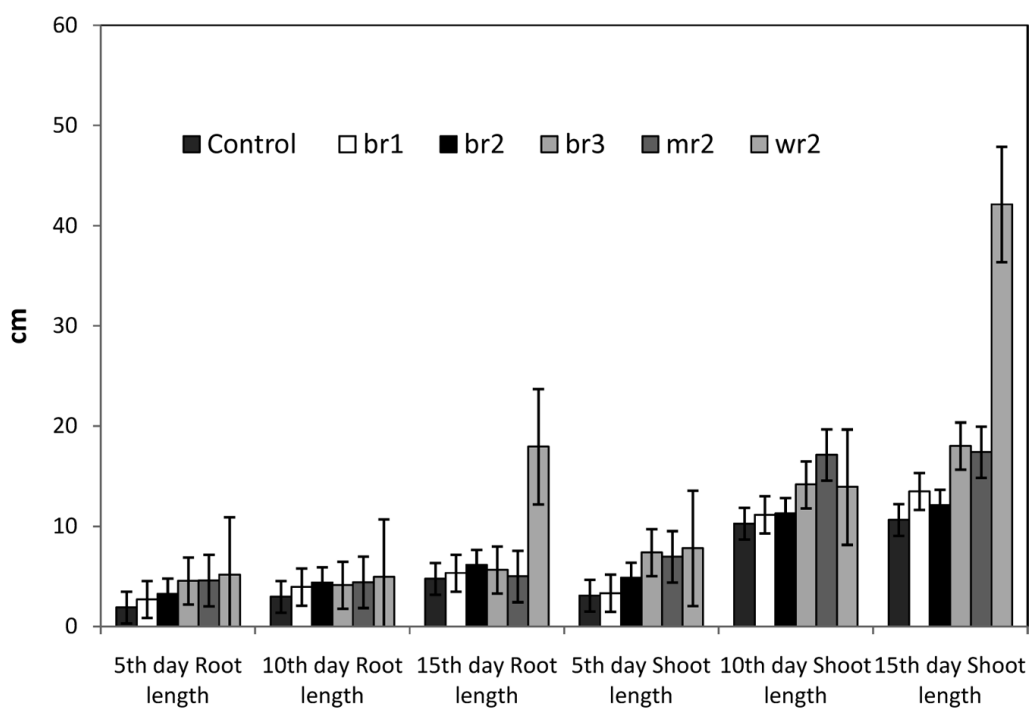

Figure 6. Growth stimulatory effect of bacterially synthesized IAA on wheat root and shoot length elongation compared with untreated control $\left(n=3^{*}\right)$ 
Table 2. Effect of IAA producing isolates on plant chlorophyll content (g/l)

\begin{tabular}{llll}
\hline Isolates & 5th day & 10th day & 15th day \\
\hline br1 & $0.0194 \pm 0.01$ & $0.0358 \pm 0.04$ & $0.0707 \pm 0.09$ \\
br2 & $0.0499 \pm 0.02$ & $0.0698 \pm 0.01$ & $0.0709 \pm 0.03$ \\
br2 & $0.0106 \pm 0.016$ & $0.0617 \pm 0.03$ & $0.0667 \pm 0.01$ \\
mr2 & $0.0875 \pm 0.002$ & $0.1117 \pm 0.03$ & $0.1536 \pm 0.02$ \\
wr2 & $0.1032 \pm 0.02$ & $0.1367 \pm 0.021$ & $0.1865 \pm 0.1$ \\
Control & $0.0100 \pm 0.04$ & $0.0493 \pm 0.01$ & $0.0572 \pm 0.002$ \\
\hline
\end{tabular}

\section{Discussion}

IAA, a member of the group of phytoharmones, is generally considered to be the most important native auxin. All ten isolates are positive for IAA production but among those five isolates br1, br2, br3, $\mathrm{mr} 2$ and wr2 were selected as potential IAA producers. Most or studies from the earlier work showed that IAA producing organisms are Gram negative (Lindow et al., 1998; Datta and Basu, 2000). Few Gram positive strains belong to Bacillus strain known to produce IAA (Wahyudi et al., 2011). Present study showed that five IAA positive strains were Gram positive.

It has been reported that IAA production by bacteria can vary among different species and strains, and it is also influenced by culture condition, growth stage and substrate availability (Mutluru and Konada, 2007). Moreover, isolates from the rhizosphere are more efficient auxin producers than isolates from the bulk soil (Sarwar and Kremer, 1992).

The use of the technique for the detection of IAA using the Van Urk Salkowski reagent is an important option for qualitative and semi-qualitative determination that assure the presence of the hormone in the supernatant of bacterial cultures or liquid formulations of biological inoculants. The amount of IAA produced by the bacteria was within the detection limits of
Salkowski reagent (Ehmann, 1977). The reagent gives reaction with IAA and does not interact with L-tryptophan and Na-acetyl-L-tryptophan and used by and large (Vaghasiat et al., 2011). Among the isolates br3 and wr2 were found to be the best producer of IAA. On the other hand br1, br2 and mr2 were found to be a medium producer of IAA as shown in Figure 2. Hence for further characterization these isolates were selected.

Auxin production by all isolates increased when culture medium supplemented with an IAA precursor; tryptophan which confirm the results of other scholar (Mutluru and Konada, 2007). Some microorganisms produce auxins in the presence of a suitable precursor such as L-tryptophan. The tryptophan increases the production of IAA in Bacillus amyloliquefaciens FZB42.Tien et al. (1979) showed that Azospirillum is able to produce auxins when exposed to tryptophan. Plants inoculated with the rhizobia together with $\mathrm{Ag}^{+}$ ion and L-tryptophan (Trp), give the highest root dry weight, and significantly increase the uptake of N, P and $\mathrm{K}$ compared to non-inoculated control plants. Karnwal (2009) tested Fluorescent Pseudomonas isolates for their ability to produce indole acetic acid in pure culture in the absence and presence of L-tryptophan and found that for both strains, indole production enhanced with increases in tryptophan concentration. 
Effect of carbon sources $(1.0 \%)$ in the basal YMD revealed that the bacterial isolates vary in their utilization and production of IAA in different carbon sources. Most of the isolates gave maximum IAA production in mannitol containing media. Effect of different nitrogen sources $(0.1 \%)$ was studied by replacing yeast extract in the original YMD medium supplemented with L-tryptophan. The isolates show differential nitrogen utilization pattern.

The effect of $\mathrm{pH}$ on IAA production differed between the Bacillus strains. The effect of $\mathrm{pH}$ on IAA is in agre with studies on other production is ement with studies on other Bacillus spp. IAA production by Bacillus spp. MQH-19 was highest at $\mathrm{pH} 6.0$ and decreased by $62 \%$ at $\mathrm{pH}$ 5.0. For Paenibacillus spp. SPT-03, IAA production was highest at $\mathrm{pH} 5.0$ and decreased by $42 \%$ at $\mathrm{pH} 7.0$ (Acuna et al., 2011).

The property of synthesizing IAA is considered as effective tool for screening beneficial microorganisms suggesting that IAA producing bacteria have profound effect on plant growth (Wahyudi et al., 2011). Inoculation with IAA producing bacteria induces the proliferation of lateral roots and root hairs. Fatima et al. (2009) also showed that germination rate, roots, shoot growth of plant were increased by IAA and PGPR. Therefore these isolates were studied for their effect on plant growth under controlled conditions. There was a significant increase in root and shoot elongation and chlorophyll contents. Among the isolates wr2 and mr2 were found much effective to show potential increase. Data obtained from pot experiment and seed germination demonstrated positive effect on plant growth and thus can be considered as plant growth promoter.

\section{Conclusion}

From this study, it is clear that rhizospheric soil can provide a rich source of IAA producing bacteria and has the ability to produce a significant amount of IAA in a tryptophan-supplemented medium. Overall ten isolates were identified as IAA producing strains among which five efficient IAA producing bacteria were characterized and media components, physical parameters were optimized for IAA production. Among the isolates wheat and maize isolates (wr2 and $\mathrm{mr} 2$ ) show best growth promoting activity. It is concluded that presence of such growth promoting rhizoflora accountable for the beneficial effects on crop growth and yield. The significance of the study could be stated as the potential of these IAA producing isolates and optimization study for IAA production will flourish the growth and ultimately IAA production in the field and prevent environmental pollution by avoiding excessive applications of industrially produced fertilizers to cultivated fields.

\section{Acknowledgements}

The author is thankful to University grants commission, New Delhi, India for financial assistance under CPE summer research project scheme and principal M J College to permit to carry out the study. Author is also grateful to Prof. Mukta Mahajan, School of languages studies and research centre, North Maharashtra University, Jalgaon for the English editing of the manuscript.

\section{References}

Acuña, J.J., Jorquera1, M.A., Martínez, O.A., Menezes-Blackburn, D., Fernández, M.T., Marschner, P., Greiner, R., Mora1, M.L. 2011. Indole acetic acid and phytase activity produced by rhizosphere bacilli as affected by $\mathrm{pH}$ and metals. Journal of Soil Science and Plant Nutrition. 11, $1-12$.

Aneja, K.R. 2001. Experiments in microbiology plant pathology and biotechnology 4th Edition.102, 106, 112, 245-275, 278. 
Arkhipchenko, I. A., Shaposhnikov, A. I., Kravchenko, L.V. 2006. Tryptophan concentration of animal wastes and organic fertilizers. Applied Soil Ecology. 34, 62-64.

Arshad, M., Frankenberger, W.T. Jr. 1992. Microbial production of plant growth regulators. In: Metting FB Jr(eds). Soil Microbial Ecol, Marcel Dekker Inc., New York. pp: 307-347.

Basu, P.S., Ghosh, A.C. 2001. Production of Indole Acetic Acid in cultures by a Rhizobium species from the root nodules of a monocotyledonous tree, Roystonea regia. Acta Biotechnol. 21, 65-72.

Carreno-Lopez, R., Campos-Reales, N., Elmerich, C. and Baca, B.E. 2000. Physiological evidence for differently regulated tryptophan-dependent pathways for indole-3-acetic acid synthesis in Azospirillum brasilense. Mol. Gen. Genet. 264, 521-530.

Costacurta, A., Vanderleyden, J. 1995. Synthesis of phytohormones by plant associated bacteria. Crit. Rev. Microbiol. 21, 1-18.

Datta, C., Basu, P. 2000. Indole acetic acid production by a Rhizobium species from root nodules of a leguminous shrub Cajanus cojan. Microbiol. Res. $155,123-127$.

Ehmann, A. 1977. The Van Urk-Salkowski reagent-a sensitive and specific chromogenic reagent for silica gel thin-layer chromatographic detection and identification of indole derivatives. Journal of Chromatography. 132, 267-276.

Fatima, Z., Saleemi, M., Zia, M., Sultan, T., Aslam, M., Riaz-ur-Rehman, Chaudhary, M.F. 2009. Antifungal activity of plant growth-promoting rhizobacteria isolates against Rhizoctonia solani in wheat. Afr. J. Biotechnol. 8, 219-225.

Ghosh, A.C., Basu, P.S. 2002. Growth behaviour and bioproduction of indole acetic acid by a Rhizobium species isolated from root nodules of a leguminous tree Dalbergia lanceolarea. Ind. J. Exp. Biol. 40,796-801.

Ghosh, S., Penterman, J.N., Little, R.D., Chavez, R., Glick, B.R. 2003. Three newly isolated plant growth-promoting bacilli facilitate the seeding growth of canola, Brassica campestris plant Physol. Biochem. 41, 277-281.

Horemans, S., K. Vlassak, 1985. Production of indol3-acetic acid by Azospirillum brasilense. In: W. Klingmuller (Ed.), Azospirillum III: genetics, physiology, Ecol. Springer-Verlag, Berlin.

Karnwal, A. 2009. Production of Indol acetic acid by fluorescent Pseudomonas in the presence of L-Tryptophan and Rice root exudates. Journal of Plant Pathology, 91, 61-63.

Khamna, S., Yokota, A., Peberdy, J.F., Lumyong, S. 2010. Indole-3-acetic acid production by Streptomyces sp. isolated from some Thai medicinal plant rhizosphere soils. Eur. Asia J. BioSci. 4, 23-32

Koga, J., Adachi, T., Hidaka, H. 1991. Molecular cloning of the gene for indolepyruvate decarboxylase from Enterobacter Caloacae. Mol. Gen. Gener. 226,10-16.

Kosuge, T., Sanger, M.1987. Indole acetic acid, its synthesis and regulation: basis for tumorigen city in plant disease. Recent Adv. Phytochem. 20,147161.

Kuang-Ren, C., Turksen, S., Umran, E., Timmer, L. W., Peter, P.U. 2003. Indole derivatives produced by the fungus Colletotrichum acutatum causing lime anthracnose and postbloom fruit drop of citrus. FEMS Microbiology Letters. 226, 23-30.

Lindow, E., Desurmont, C, Elkins, R, Mccourt,y G, Clark, E., Maria, T.B. 1998. Occurrence of Indole 3- acetic acid-producing bacteria on pear trees and 
their association with fruit russet. Phytopothol. 88, 1149 - 1157.

Lynch, J.M. 1985. Origin, nature and biological activity of aliphatic substances and growth hormones found in soil. In: Vaughan, D., Malcom, R. E. (Eds). Soil Organic Matter and Biological Activity. Martinus Nijhoff/Dr. W. Junk Publishers. Dordrecht, Boston, Lancaster. pp. 151-174.

MacFaddin, J.F. 2000. Biochemical tests for identification of medical bacteria. Williams and Wilkins, London

Mandal, S.M., Mondal, K.C., Dey, S., Pati, B.R. 2007. Optimization of cultural and nutritional conditions for indole-3-acetic acid (IAA) production by a Rhizobium sp. isolated from root nodules of Vigna mungo (L.) Hepper. Res. J. Microbiol. 2, 239-246.

Manulis, S., Shafri,r H., Epstein, E., Lichter, A., Barash, I. 1994. Biosynthesis of Indole 3-acetic acid via the indole 3 -acetamide pathway in Streptomyces spp. Microbiology. 140, 1045-1050.

Matsukawa, E., Nakagawa, Y., Iimura, Y., Hayakawa, M. 2007. Stimulatory effect of indole-3acetic acid on aerial mycelium formation and antibiotic production in Streptomyces spp. Actinomycetologica. 21, 32-39.

Oberhansli, T., Defago, G.,Haas D. 1991. Indole3 -acetic acid (IAA) synthesis in the biocontrol strain CHAO of Pseudomonas fluoresces: role of tryptophan side chain oxidase. J. Gen. Microbial. 137, 2273-2279.

Pattern, C.L., Glick, B.R. 2002. Role of Pseudomanas putida indo lactic acid in development of the host plant root system. App. Eniron. Microbeal. 68, 3795-3801

Sarwar, M., Kremer, R.J. 1992. Determination of bacterially derived auxins using a microplate method. Lett. Appl. Microbiol. 20, 282-285.
Shih-Yung, H. 2010. IAA production by Streptomyces scabies and its role in plant microbe interaction. Msc thesis, Cornell University.

Shilts, T., Erturk, U., Patel, N.J., Chung, K.R. 2005. Physiological regulation of biosynthesis of Indole-3 -acetic acid and other indole derivatives by the citrus fungal pathogen Collectotrichum acutatum. Journal of Biological Sciences. 5, 205210.

Sudha, M., Shyamala, G.R., Prbhavati, P., Astapritya, P., Yamuna Devi, Y., Saranya, A. 2012. Production and optimization of Indole acetic acid by indigenous microflora using agro waste as substrate. Pakistan Journal of Biological Sciences. 15, 39-43.

Swain, M.R., Naskar, S.K., Ray, R.C. 2007. Indole 3 -acetic acid production and effect on sprouting of yam. (Dioscorea rotundata L) Minisetts by Bacillus subtilis Isolated from culturable cowdung microflora. Polish Journal of Microbiology. 56, 103-110.

Tien, T.M., Gaskinsa, M.H., Hubbell1, N.D.D. H. 1979. Plant growth substances produced by Azospirillurn brasilense and their effect on the growth of pearl millet (Pennisetum americanum L.).Appl. Environ. Microbiol. 37, 1016-1024.

Vaghasiat, H.L., Patel, G.M., Chudasama, R.S., Bhott, K.R. 2011. Screening of IAA from rhizospher microflora of field crops. Bioscience Discovery. 02, 94-100.

Wahyudi,A.T.,Astuti, R.P., Widyawati,A., Meryandini, A., Nawangsih, A. A. 2011. Characterization of Bacillus sp. strains isolated from rhizosphere of soybean plants for their use as potential plant growth for promoting Rhizobacteria. Journal of Microbiology and Antimicrobials. 3, 34-40.

Zhao, Y. 2010. Auxin biosynthesis and its role in plant development. Annu. Rev. Plant Biol. 61, 49-64. 